\title{
Coverage of China New Generation Weather Radar Network
}

\author{
Chao Min,, ${ }^{1,2}$ Sheng Chen $\mathbb{D}^{1,2}$ Jonathan J. Gourley, ${ }^{3}$ Haonan Chen, ${ }^{4,5}$ Asi Zhang, ${ }^{1,2}$ \\ Yong Huang $\mathbb{D}^{6}{ }^{6}$ and Chaoying Huang ${ }^{7}$
}

\author{
${ }^{1}$ School of Atmospheric Sciences, Guangdong Province Key Laboratory for Climate Change and Natural Disaster Studies, \\ Sun Yat-sen University, Guangzhou 510275, China \\ ${ }^{2}$ Southern Marine Science and Engineering Guangdong Laboratory (Zhuhai), Zhuhai 519082, China \\ ${ }^{3}$ NOAA/National Severe Storms Laboratory, Norman 73072, USA \\ ${ }^{4}$ Colorado State University, Fort Collins 80523, USA \\ ${ }^{5}$ NOAA/Earth System Research Laboratory, Boulder 80305, USA \\ ${ }^{6}$ Anhui Meteorological Bureau, Hefei 230061, China \\ ${ }^{7}$ Key Laboratory of Environment Change and Resources Use in Beibu Gulf, Guangxi Teachers Education University, \\ Nanning 530011, China
}

Correspondence should be addressed to Sheng Chen; chensheng@mail.sysu.edu.cn

Received 10 March 2019; Revised 11 May 2019; Accepted 20 May 2019; Published 16 June 2019

Guest Editor: Dongkyun Kim

Copyright (c) 2019 Chao Min et al. This is an open access article distributed under the Creative Commons Attribution License, which permits unrestricted use, distribution, and reproduction in any medium, provided the original work is properly cited.

\begin{abstract}
The China Meteorological Administration has deployed the China New Generation Weather Radar (CINRAD) network for severe weather detection and to improve initial conditions for numerical weather prediction models. The CINRAD network consists of 217 radars comprising $123 \mathrm{~S}$-band and $94 \mathrm{C}$-band radars over mainland China. In this paper, a high-resolution digital elevation model (DEM) and beam propagation simulations are used to compute radar beam blockage and evaluate the effective radar coverage over China. Results show that the radar coverage at a height of $1 \mathrm{~km}$ above ground level (AGL) is restricted in complex terrain regions. The effective coverage maps at heights of $2 \mathrm{~km}$ and $3 \mathrm{~km}$ AGL indicate that the Yangtze River Delta, the Pearl River Delta, and North China Plain have more overlapping radar coverage than other regions in China. Over eastern China, almost all areas can be sampled by more than 2 radars within $5 \mathrm{~km}$ above mean sea level (MSL), but the radars operating in Qinghai-Tibet Plateau still suffer from serious beam blockage caused by intervening terrain. Overall, the radars installed in western China suffer from much more severe beam blockage than those deployed in eastern China. Maps generated in this study will inform users of the CINRAD data of their limitations for use in precipitation estimation, as inputs to other weather and hydrological models, and for satellite validation studies.
\end{abstract}

\section{Introduction}

As the climate changes, the temporal and spatial distributions of precipitation characteristics are experiencing changes. Torrential precipitation events have become more frequent [1-3], which often lead to floods and debris flows causing large property damages and casualties. With the high spatiotemporal continuity of radar data, forecasters can identify the location of heavy precipitation and issue early warnings and watches. Understanding realistic spatial coverage maps associated with an operational radar network is vital for using the data in applications $[4,5]$. Klazura and Imy simulated a coverage map at $10,000 \mathrm{ft}$ (about $3.0 \mathrm{~km}$ ) above the radar site level for radar sites in the contiguous United States (CONUS), showing vast areal coverage extents even in the western United States [6]. Nevertheless, the altitude of western WSR-88D sites varies greatly (the elevation of radar sites ranges from near sea level to more than $10,000 \mathrm{ft}$ ). Some researchers have pointed out that precipitation is orographically enhanced within $1-2 \mathrm{~km}$ above the topography [7-9]. Thus, Klazura and Imy optimistically overestimated the radar coverage over western mountains, and it is difficult to interpret meaningful information from their work of a radar coverage map $[10,11]$. Westrick et al. evaluated the limitation of the WSR-88D radar network over the mountainous West of the US and defined that the radar 
scanning range is effective if more than $50 \%$ of the beam is unblocked [11]. Subsequently, Maddox et al. developed radar coverage maps over the CONUS in more detail [10]. More reports about the terrain blockage of regional radars can be found in $[12,13]$.

When constructing a weather radar network, terrain blockage is a significant factor to affect siting radars. Considering this, Minciardi et al. developed an approach to optimally deploy the weather radar network in Italy [14]. Inggs et al. provided a quantitative method for evaluating radar coverage to improve future construction and siting of radars [15]. Weather radar data are the most reliable remote sensing data in detecting precipitation. However, the radar beam usually encounters partial or total beam blockage caused by high buildings and mountains. Additionally, some previous studies use beam propagation models to provide beam blockage correction factors to enhance precipitation estimates. The bias between radar quantitative precipitation estimation (QPE) and ground gauge data will be reduced by using these factors [16-19]. Geng and Katsumata analysed beam blockage of radars on board the Mirai and showed that details about beam blockage improves quality control of radar data of Mirai [4].

Similar to the NEXRAD network in the US, the China Meteorological Administration (CMA) has deployed the China Next Generation Weather Radar (CINRAD) network. Currently, the CINRAD network is composed of 217 Doppler weather radars (94 C-band radars and 123 S-band radars) over mainland China. These radars are distributed densely across China except in complex terrain where beam blockages are more likely to have negative consequences on derived quantitative precipitation estimation (QPE) $[11,12,20]$. Additionally, there are four WSR-88D radars installed in Taiwan and one WSR-98D radar installed in Hong Kong. Previous studies evaluated the radar coverage over selected regions of southern China where the topography is relatively flat compared to western China, indicating decent coverage [21]. Wang et al. expanded the study of radar coverage to mainland China using a single tilt at 0.5degree elevation angle [22]. However, the national CINRAD coverage map still needs to be investigated and improved due to the absence of effective coverage by higher elevation angles. Furthermore, the CMA has supplemented 58 more radars over China since the initial study of CINRAD coverage had approximately 160 radars in 2011 [22]; thus, the effective coverage maps need to be updated accordingly. Therefore, it is necessary to investigate the radar network's coverage over China which can serve as an important reference for radar data users, especially for weather forecasters in operational offices. In order to make better use of weather radar network for monitoring and early warning of extreme weather events, this study quantifies the coverage of the renewed radar network over China, including four radars in Taiwan and the one in Hong Kong.

\section{Methodology}

2.1. Study Area. The complex topography in China shows a staircase-like distribution from low altitude in the east to high altitude in the west. Spatiotemporal precipitation spectra show a significant diurnal and seasonal variation over China $[23,24]$. Heavy precipitation is common in summer, and these storms can trigger severe floods and mudslides. Figure 1 depicts the digital elevation map of China and the distribution of the CINRAD network. The altitude ranges from near sea level to more than $8000 \mathrm{~m}$ over the Qinghai-Tibet Plateau. In total, there are 222 radars (composed of $128 \mathrm{~S}$-band and $94 \mathrm{C}$-band radars) in operation to detect weather phenomena over China when the radars in Hong Kong and Taiwan are taken into account. $S$-band radars have the advantage of detecting precipitation from longer distances $(\sim 460 \mathrm{~km})$ with little attenuation in rain. Geographically, eastern China is much flatter than western China (such as the Tibet plateau). Economically, most of large cities (e.g., Beijing, Shanghai, Shenzhen, and Guangzhou) are in eastern China where more than $90 \%$ of population lives. The total gross domestic product (GDP) of these cities accounts for more than $90 \%$ of the total GDP of China. Meteorologically, eastern China is impacted significantly by the East Asia monsoon which brings a lot of disastrous heavy precipitation events including tornadoes and typhoons. Therefore, S-band radars are deployed in eastern China to help monitor heavy precipitation events and provide early warnings for the government and the public when the radar observations are assimilated in the numerical forecast models like the Weather Research and Forecasting (WRF) model. In contrast, western China has lots of high-altitude mountains like Kunlunshan Mountain in Tibet plateau and Hengduan Mountains in southeastern Qinghai plateau. These mountains cause serious radar beam blockage. Additionally, few people live in the western China where the GDP is a small percentage of the total GDP of China. Furthermore, few disastrous weather events occur and the precipitation intensity is weaker than that in the middle and eastern China. For these reasons, it makes sense to use the lower-cost C-band radars in western China despite the disadvantages with shorter ranges for precipitation detection and reflectivity losses in rain due to attenuation of the radar signal.

The radar distributions are sparse in the west especially on the Qinghai-Tibet Plateau, while the radars are more closely spaced in the east. A national map of slope derived from 30 arc sec $(90 \mathrm{~m})$ Shuttle Radar Topography Mission (SRTM) high-resolution digital elevation model (DEM) data by using ArcGIS, which is one of the contributing factors for landslides, is shown in Figure 2. The steep slope areas are Tianshan Mountains, northern Qinghai-Tibet Plateau, south-eastern Qinghai-Tibet Plateau, Yunnan-Guizhou Plateau, and northern Sichuan province where radars are distributed more sparsely. Figure 3 shows the ideal coverage map of CINRAD without beam blockage and national meteorological stations. The shaded area represents coverage (without beam blockage) of $230 \mathrm{~km}$ for S-band and $150 \mathrm{~km}$ for C-band radar. There are large areas in south-eastern XinJiang, Qinghai-Tibet Plateau, and northern Inner Mongolia with no radar coverage while almost the rest of China is well detected by the CINRAD network in this optimal coverage map. The complex topography in China 


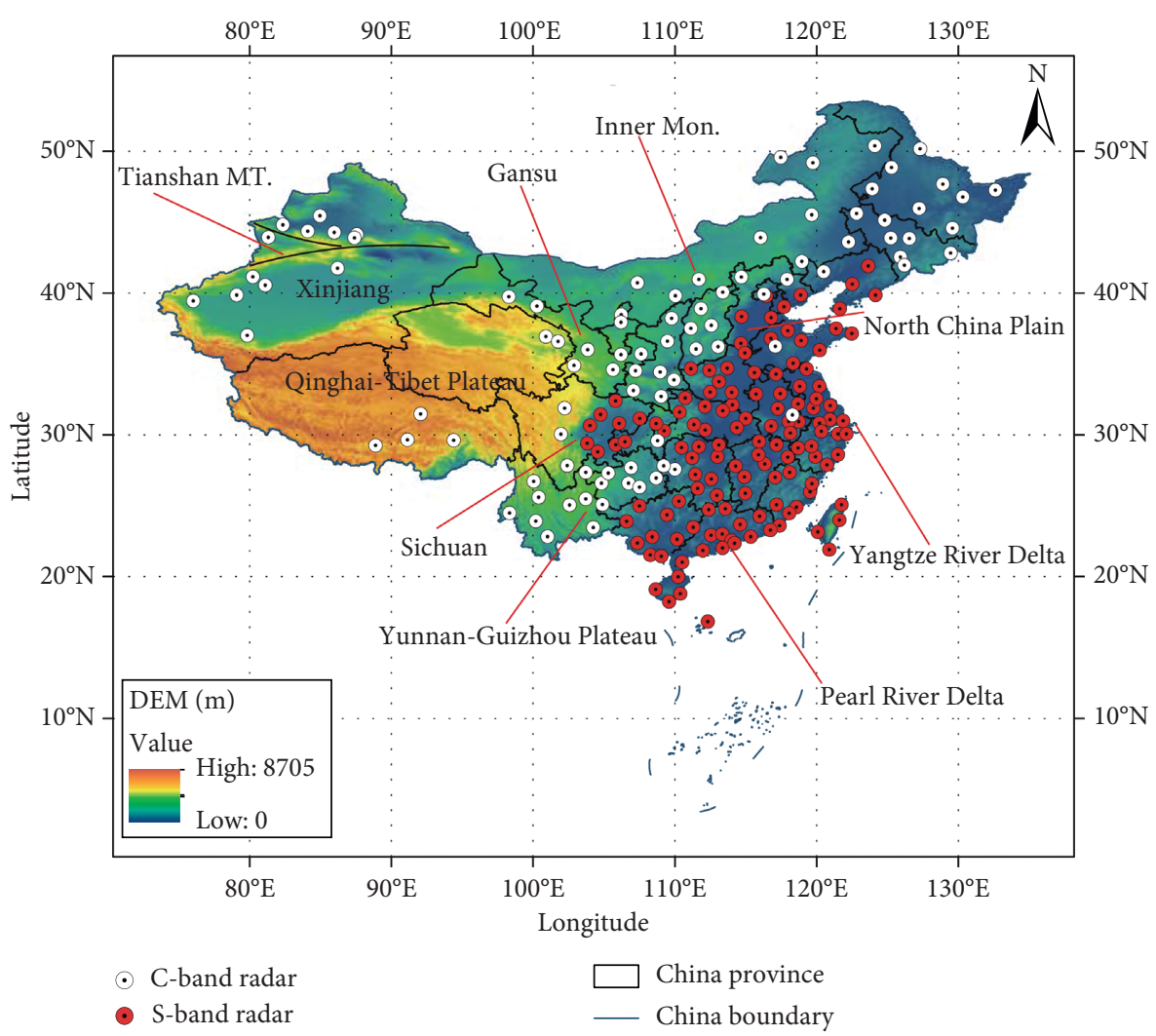

Figure 1: Topography $(\mathrm{m})$ map of China with distributions of the CINRAD. White dots represent C-band radars, and red dots denote the Sband radars.

will induce serious beam blockages causing bias in radar quantitative precipitation estimation (QPE) especially in mountainous western China. Meanwhile, the ground-based gauges are rare in these areas without radar coverage, especially on the Qinghai-Tibet Plateau called water tower of Asia. It is difficult to make accurate precipitation forecast there due to the lack of radar coverage and the sparseness of ground-based gauges.

2.2. Data and Computing Method. The $30 \operatorname{arc} \sec (90 \mathrm{~m})$ Shuttle Radar Topography Mission (SRTM) high-resolution digital elevation model (DEM) data (available at http://srtm. csi.cgiar.org/SELECTION/inputCoord.asp) are used in this study to depict the terrain over China and then compared with the height of the center of the radar beam. Similar analysis methods $[10,11]$ have been employed to compute radar coverage over the US. It is known that the antenna elevation angle depends on the scan strategies employed for the network. The new generation weather radar supplies two volume coverage patterns (VCP), namely, precipitation scan mode and clear sky scan mode. The precipitation scan mode contains two VCPs (i.e., VCP-11 and VCP-21). In operational practice, VCP-21 is generally used while VCP-11 is rarely used. The VCP-21 scan mode is to complete 9 elevation tilts' scans (e.g., $0.5^{\circ}, 1.5^{\circ}, 2.4^{\circ}, 3.4^{\circ}, 4.3^{\circ}, 6.0^{\circ}, 9.9^{\circ}$, $14.6^{\circ}$, and $19.5^{\circ}$ ) within 6 minutes. In order to alleviate beam blockage caused by complex topography, the hybrid scan is constructed from a composite of elevation angles to optimize low-level coverage needed for precipitation estimation [25].
Now, radar data users usually use whichever elevation angle is closest (and above) to the ground. So, the lowest $0.5^{\circ}$ elevation angle is now used when the area of concern is closer to radar [26]. According to this, this paper applies the new method, which is illustrated in Figure 4, to evaluate realistic radar coverage. For instance, when the radar beam encounters a mountain in the propagation path and the mountain is high enough to obstruct the radar beam up to $50 \%$, the second tilt will be adopted. If the mountain is still too high to overcome and the radar beam is still blocked by $50 \%$ or more, the third tilt will be adopted. The remaining tilts can be adopted in the same manner.

The following principles are used in this study. Firstly, the location information (longitude, latitude, and altitude) of each radar site is determined and mapped with the DEM data around the radar site. The height of the center of the beam at each sampling point (every $50 \mathrm{~m}$ for a sampling point) is calculated with range at each azimuthal angle (at intervals of $0.1^{\circ}$ ). Next, the height of the beam center is compared with the corresponding point on the DEM and if the center of the radar beam is lower than the terrain, it is considered to be blocked and no longer propagates at farther ranges. The height of the radar beam is computed by the following equation with the assumption that the radar beam propagates in standard atmosphere [27]:

$$
h=\sqrt{r^{2}+R^{2}+2 r R \sin (\theta)}-R+h_{0},
$$

where $h$ is the height of radar beam, $r$ is the range from radar site, $R$ (approximately $8500 \mathrm{~km}$ ) is the effective earth radius 

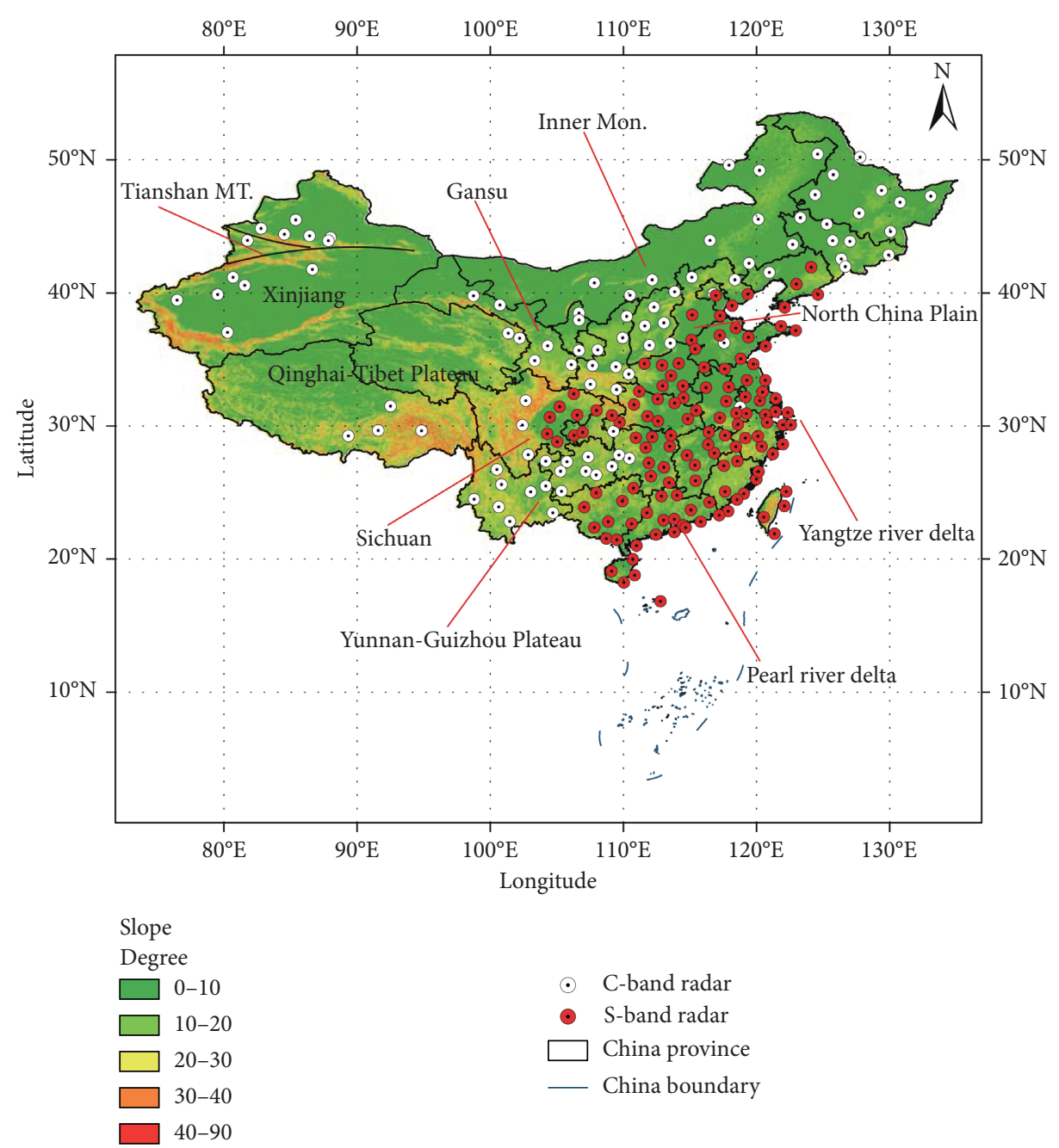

$\odot$ C-band radar

- S-band radar

China province

China boundary

FIGURE 2: Slope (degree) map of China showing distributions of the CINRAD. White dots represent C-band radars, and red dots refer to the S-band radars.

obeying standard atmospheric refraction, $\theta$ is the elevation angle, and $h_{0}$ is the height of radar antenna. The range of a radar scan is limited by earth curvature, intervening blockages and attenuation of the radar signal. Attenuation is more prevalent with C-band radars, so this study computes the radar coverage out to $230 \mathrm{~km}$ for S-band radars and $150 \mathrm{~km}$ for C-band radars. Key specifications of the CINRAD systems are shown in Table 1.

To verify the beam propagation simulation effectiveness, the reflectivity of example radars (Shenzhen radar and Zhuhai radar) and simulation results are presented in Figure 5. Figures 5(a) and 5(c) show the radar coverage of the first tilt $\left(0.5^{\circ}\right)$ of Shenzhen radar and Zhuhai radar revealing a similarity with the corresponding reflectivity maps (Figures 5(b) and 5(d)) though there are some notable differences too. These inconsistencies may be caused by ground clutter, biological scatterers, sea clutter, etc. This indicates that beam propagation simulations used in this study can effectively depict the terrain blockage. Further validation would be possible using reflectivity observations in widespread rain.

\section{Results}

In this study, both radar coverage maps at heights above ground level (AGL) and constant altitudes in MSL are calculated to estimate the coverage condition of the CINRAD network. Heights of $1 \mathrm{~km}, 2 \mathrm{~km}$, and $3 \mathrm{~km}$ AGL and $3 \mathrm{~km}$ and $5 \mathrm{~km}$ MSL are set as constraints.

During the cool season, the height of the bright band is relatively low and orographic precipitation processes enhance growth in the lowest 1-2 km above topography [7-9]. When radar data users are applying the measurements for studying or monitoring storms where microphysical and dynamical processes occur at low levels (e.g., cool season precipitation and quasi-linear convective system tornadoes), radar data should be gathered near the ground [10]. Correspondingly, radar coverage at $1 \mathrm{~km}$ and $2 \mathrm{~km}$ AGL are shown in Figures 6(a) and 6(b), respectively. Figure 6(a) shows that there are large areas with no radar coverage in western China especially on the Qinghai-Tibet Plateau. In addition, there are severe beam blockages on the YunnanGuizhou Plateau owing to the complex terrain. However, an 


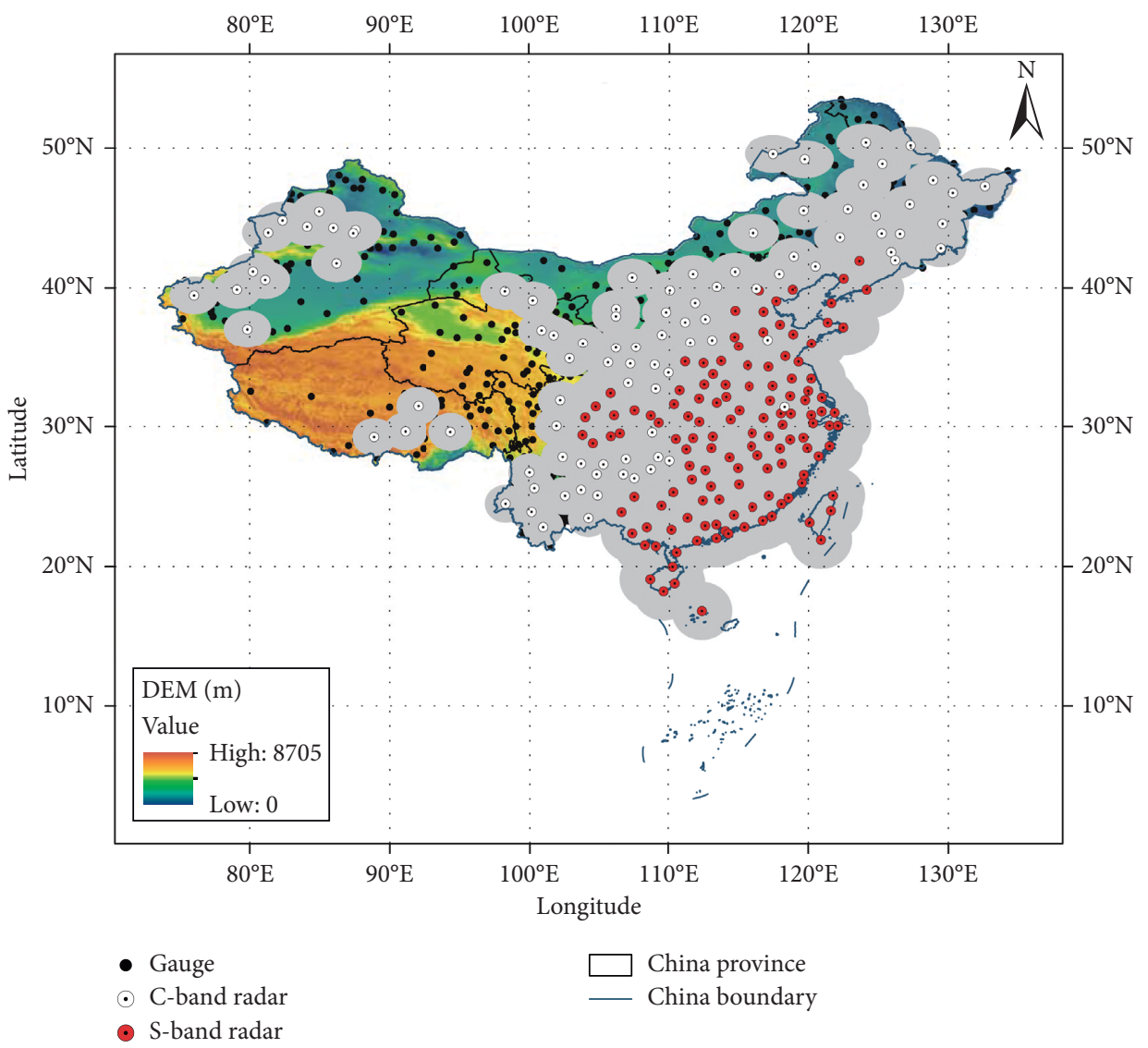

FIGURE 3: CINRAD coverage map (without beam blockage) of $230 \mathrm{~km}$ for S-band and $150 \mathrm{~km}$ for C-band radar. White dots represent Cband radars, red dots denote the S-band radars, and black dots refer to national meteorological stations.

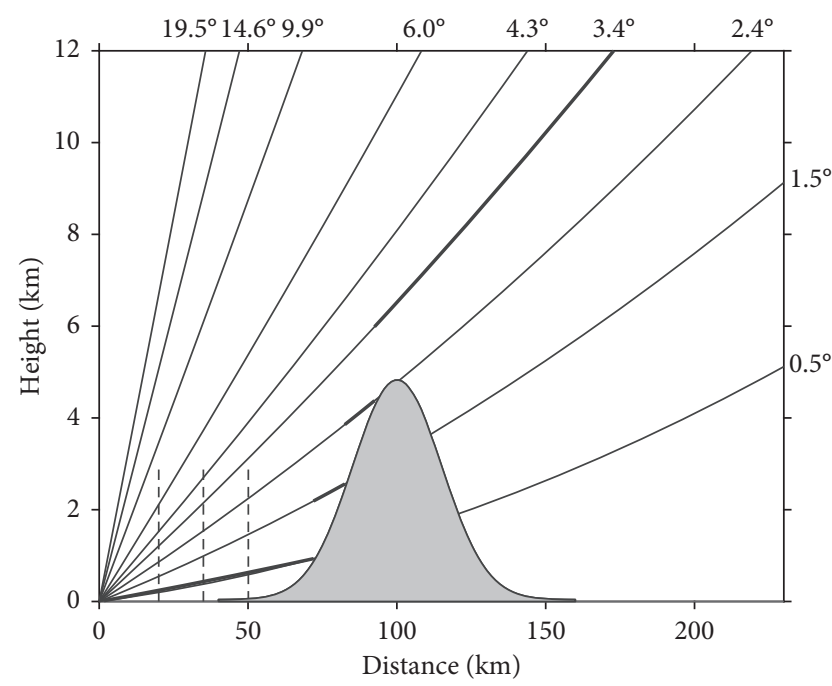

FIGURE 4: The computing method of radar effective coverage using all elevation tilts with considering terrain blockage. The radar is supposed to locate at original point $(0,0)$. The shadowed area denotes a mountain which blocks radar beams. The black bold lines are the adopted beams from the radar, and the dash lines represent different distances (e.g., $20 \mathrm{~km}, 35 \mathrm{~km}$, and $50 \mathrm{~km}$ ) from radar site.

exception is that the radar coverage in the northern regions of Tianshan Mountains in Xinjiang province is relatively good. In contrast to the coverage status in the western area,
TABle 1: System specifications of China Next Generation Weather Radars.

\begin{tabular}{lcc}
\hline Radar type & S-band radar & C-band radar \\
\hline Wavelength $(\mathrm{cm})$ & $\sim 10$ & $\sim 5.6$ \\
Antenna gain $(\mathrm{dB})$ & $\geq 44$ & $\geq 43$ \\
Diameter of the antenna dish $(\mathrm{m})$ & $8 \sim 9$ & 4.5 \\
Range resolution $(\mathrm{m})$ & $\leq 150$ & $\leq 150$ \\
Beam width $\left({ }^{\circ}\right)$ & $\leq 1.0$ & $\leq 1.0$ \\
Pulse power $(\mathrm{kW})$ & $\geq 650$ & $\geq 250$ \\
Noise figure $(\mathrm{dB})$ & $\leq 4$ & $\leq 4$ \\
Dynamic range $(\mathrm{dB})$ & $\geq 95$ & $\geq 95$ \\
\hline
\end{tabular}

overlapping radar coverage in eastern China is better at $1 \mathrm{~km}$ AGL. Radar coverage at $2 \mathrm{~km}$ AGL (Figure 6(b)) depicts limited coverage in western China while the CINRAD network covers the east quite well. For example, there are more than 3 radars overlapping in the Yangtze River Delta and the Pearl River Delta, which are the important economic and prosperous areas in China. Generally speaking, when areas are covered by more than one radar, the radar QPE will be more accurate. Because biases of radar QPE increase with longer ranges from the radar site, low-level coverage is maximized using radar data that have been mosaicked $[17,28]$. However, the steep slope areas (e.g., Tianshan Mountains, northern Qinghai-Tibet Plateau, south-eastern Qinghai-Tibet Plateau, Yunnan-Guizhou Plateau, and 


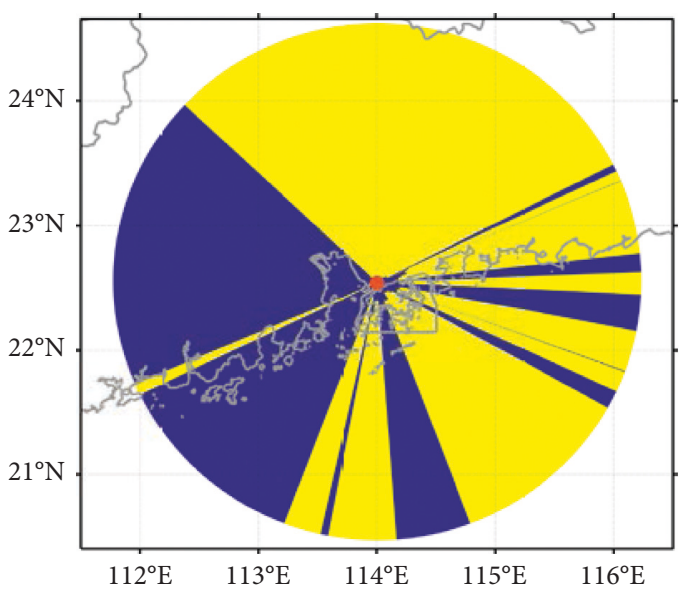

(a)

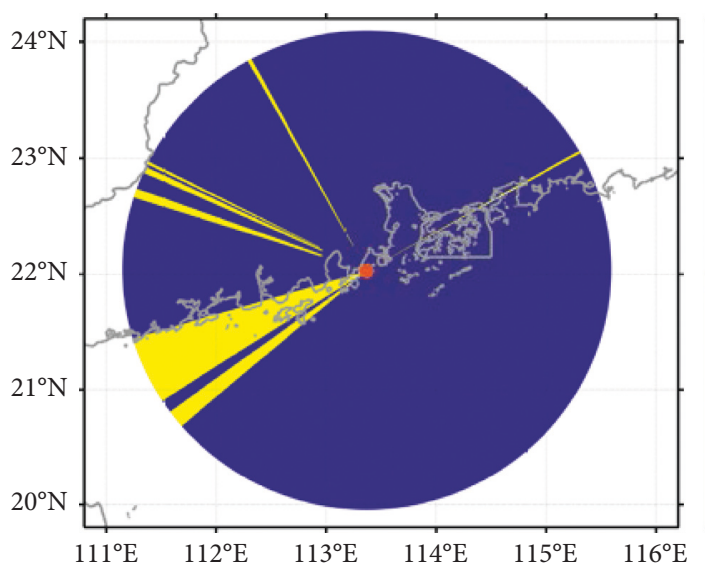

(c)
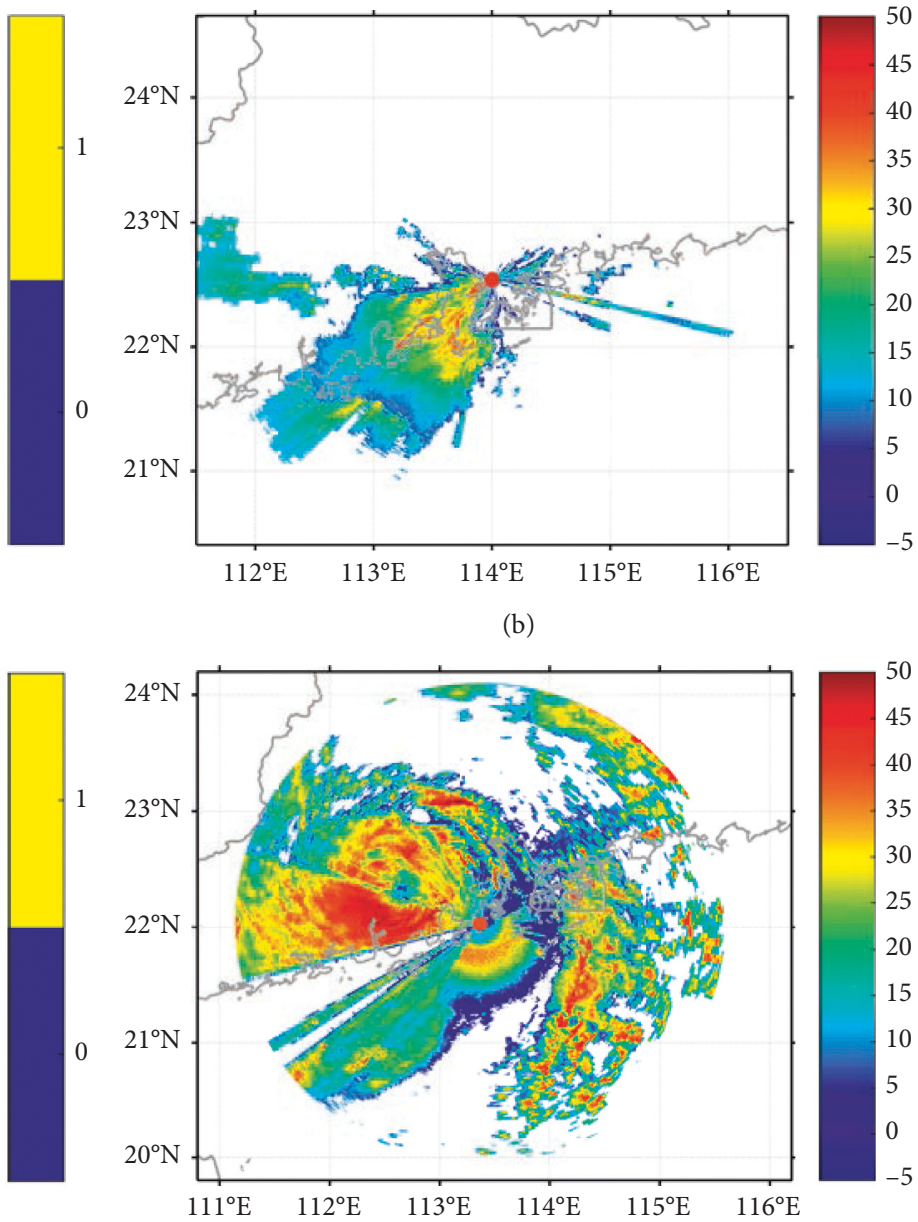

(d)

FIgURE 5: (a) The effective coverage map of Shenzhen radar using the first tilt $\left(0.5^{\circ}\right)$ simulation, and the blue area denotes coverage area while the yellow area represents no radar coverage area. (b) The reflectivity at UTC 00004 September 2017 is used to validate the simulation result. (c) The effective coverage map of Zhuhai radar using the first tilt $\left(0.5^{\circ}\right)$ simulation, and the blue area refers to coverage area while the yellow area indicates no radar coverage area. (d) The reflectivity at UTC 151223 August 2017 is used to validate the simulation result. The red dot corresponds to the radar site.

northern Sichuan province) shown in Figure 2 are almost with little radar coverage according to Figures 6(a) and 6(b). Topographic slope is a contributing factor for landslides when heavy precipitation occurs. So, it will be challenging to issue early warnings and watches of heavy precipitation, mudslides, and landslides in these regions.

The CINRAD network coverage map at a height within $3 \mathrm{~km}$ AGL is exhibited in Figure 6(c). It is noted that the coverage and overlapping maps are to some extent different from those in Wang et al. [22]. The main reasons why these two coverage maps are different are as follows: Firstly, 58 radars have been added to the CINRAD network since the initial study. Secondly, the merged data of multiple elevation angles to construct the hybrid scan represent the coverage map in this paper. In the new coverage map shown in Figure 6(c), it can be seen that western China suffers from restricted coverage at $3 \mathrm{~km}$ AGL except the northern Xinjiang province and some regions of the southern Tianshan Mountains. Eastern China and central
China are well sampled by the CINRAD network except for some parts of the northeast where radars are sparse. For instance, there are large areas covered by as many as 3-6 radars in the North China Plain and 4-7 radars in the Pearl River Delta area. The Yangtze River Delta is sampled by 4-9 radars. Therefore, it is best covered by the CINRAD network in China and facilitates water resources management, severe thunderstorm monitoring and warning, and forecasting through assimilation in numerical weather prediction models. In summer, precipitation amounts, occurrence frequencies, and intensities reach their peak values in most of China, especially in the eastern QinghaiTibet Plateau and Yunnan-Guizhou Plateau where there is sparse radar coverage $[23,24]$. Plus, the freezing levels are higher compared to the cool season. Thus, the radar coverage map at $3 \mathrm{~km}$ AGL in Figure 6(c) is a preferable reference for interpreting the capability of the CINRAD network to detect warm season storms. For the QinghaiTibet Plateau, the large data voids present great challenges 


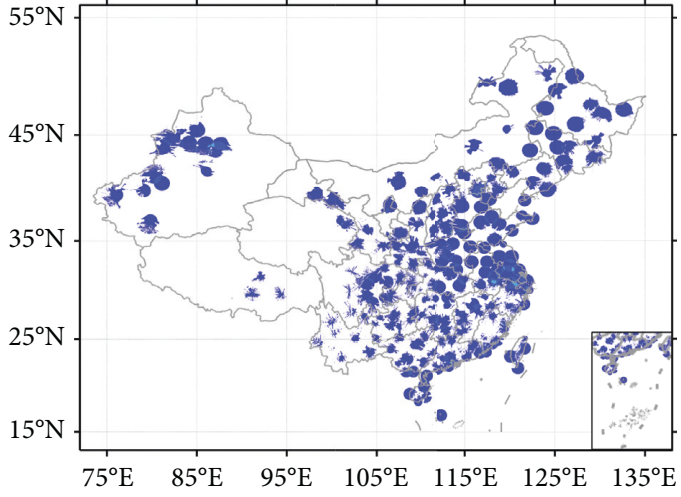

(a)
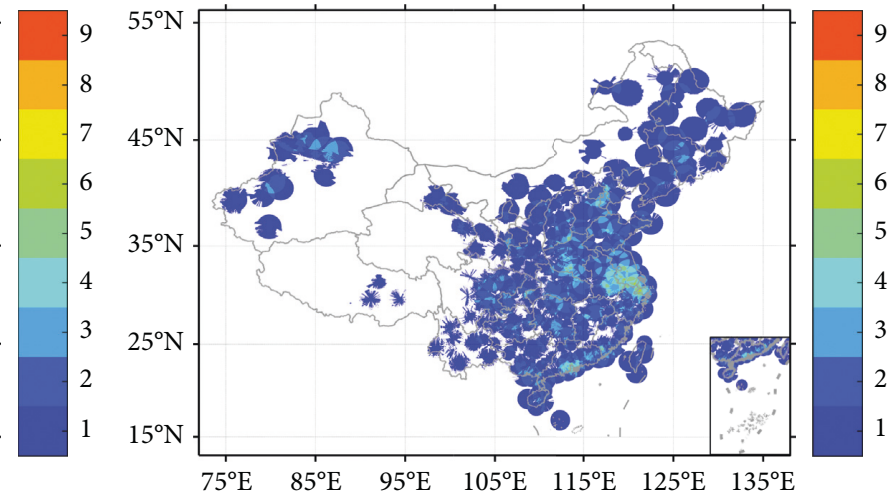

(b)

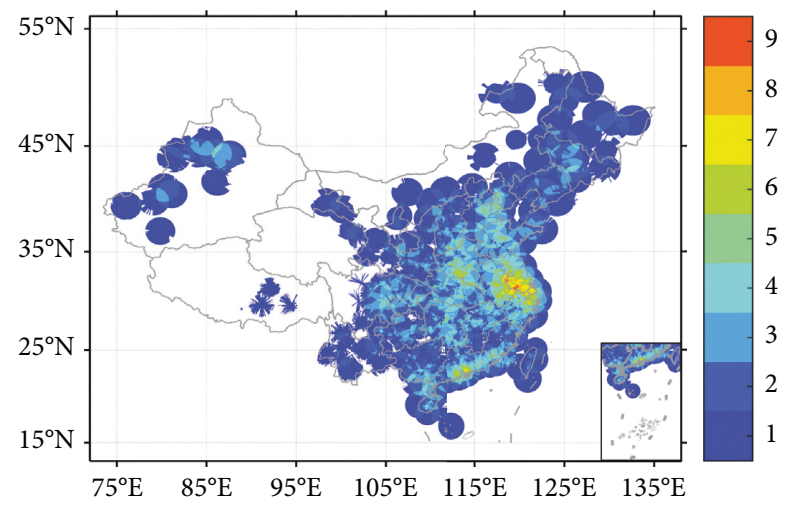

(c)

Figure 6: Effective coverage map of CINRAD network at heights of (a) $1 \mathrm{~km}$, (b) $2 \mathrm{~km}$, and (c) $3 \mathrm{~km}$ AGL over China. The legend refers to the number of overlapping radars covering a given point in space, and the subgraph at the bottom right corner of each panel represents the South China Sea.

for radar data users to estimate precipitation occurring in this region.

The atmospheric conditions like temperature, wind, troughs, and ridges are usually analysed at mandatory levels of $700 \mathrm{hPa}$ pressure level and $500 \mathrm{hPa}$ pressure level in weather forecast. Gou et al. calculated the maximum ranges of radar coverage and the altitudes of multiradar hybrid mosaic reflectivity over eastern Sichuan province (e.g., wellcovered area in this study) and further studied radar reflectivity for storms at different altitudes and propagation directions [29]. So, CINRAD coverage maps at heights above MSL are also estimated in this study with the aim of offering reference when designing mosaicking schemes for locations that are covered by more than one radar. Figures 7 (a) and 7(b) show the CINRAD network coverage at a height of $3 \mathrm{~km}$ above MSL (i.e., near the $700 \mathrm{hPa}$ isobaric surface) and $5 \mathrm{~km}$ above MSL (i.e., near the $500 \mathrm{hPa}$ isobaric surface), respectively. Figures $6(\mathrm{c})$ and $7(\mathrm{a})$ show a significantly different situation in terms of coverage in western China. As shown in Figure 7(a), there are larger areas with data voids at a height of $3 \mathrm{~km}$ above MSL because the elevation of many radar sites in western China is at or higher than $3 \mathrm{~km}$ above MSL. There is nearly no radar coverage on the Qinghai-Tibet Plateau and very poor radar coverage on the YunnanGuizhou Plateau, Inner Mongolia Autonomous Region
(Inner Mon.), Gansu province, and the southeastern Xinjiang province. In contrast, the radar coverage map (Figure $7(\mathrm{a})$ ) reveals overlapping coverage in the east, sampled by more than 2 radars in the North China Plain, the Pearl River Delta area, and the Yangtze River Delta. The coverage map of the CINRAD network at a height of $5 \mathrm{~km}$ above MSL still shows limitations in the west, while eastern China and central China are almost completely covered with more than 2 radars overlapping in almost all regions (Figure $7(\mathrm{~b})$ ). There are more than 4 radars overlapping in the North China Plain, southern China, eastern Sichuan province, and the Yangtze River Delta.

For further analysis, radar coverage indexes such as coverage area (including the border areas and coastal areas) and coverage ratio are also used in this study. As seen in Table 2, the statistical result shows that the CINRAD coverage area of $1 \mathrm{~km}$ AGL (AGL1) is about $2.5 \times 10^{6} \mathrm{~km}^{2}$ and the coverage ratio is about $26 \%$. With the increasing of height of AGL and height above MSL, the coverage area and ratio are increasing. The coverage area of $2 \mathrm{~km}$ AGL (AGL2) is about $5.3 \times 10^{6} \mathrm{~km}^{2}$, and the coverage ratio is about $55 \%$, respectively. Within $3 \mathrm{~km}$ AGL, the coverage area and ratio are about $6.6 \times 10^{6} \mathrm{~km}^{2}$ and $69 \%$, respectively. Within $3 \mathrm{~km}$ above MSL, the coverage area and ratio are similar to these indexes within $2 \mathrm{~km}$ AGL. The coverage area $\left(7.0 \times 10^{6} \mathrm{~km}^{2}\right)$ 


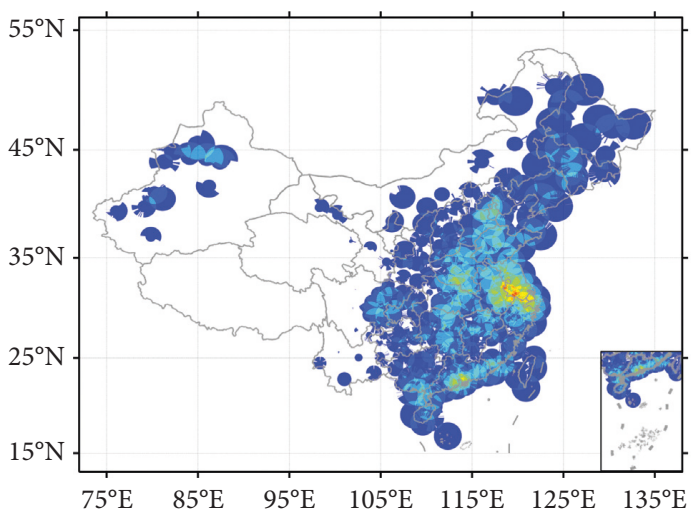

(a)

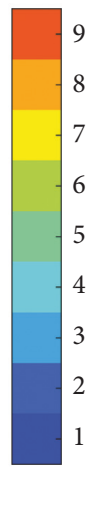

$55^{\circ} \mathrm{N}$
$45^{\circ} \mathrm{N}$
$35^{\circ} \mathrm{N}$
$25^{\circ} \mathrm{N}$
$15^{\circ} \mathrm{N}$

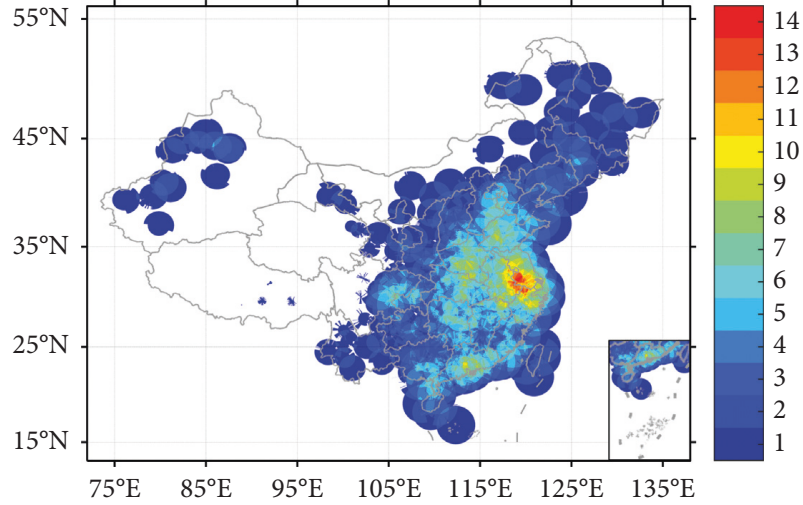

(b)

FIgURE 7: Effective coverage map of CINRAD network at heights of (a) $3 \mathrm{~km}$ and (b) $5 \mathrm{~km}$ above MSL over China. The legend refers to the number of overlapping radars covering a given point in space and the subgraph at the bottom right corner of each panel represents the South China Sea.

TABle 2: Coverage index of China Next Generation Weather Radars.

\begin{tabular}{lcc}
\hline Height & Coverage area $\left(\mathrm{km}^{2}\right)$ & Coverage ratio $(\%)$ \\
\hline AGL1 & $2.5 \times 10^{6}$ & 26 \\
AGL2 & $5.3 \times 10^{6}$ & 55 \\
AGL3 & $6.6 \times 10^{6}$ & 69 \\
MSL3 & $5.3 \times 10^{6}$ & 55 \\
MSL5 & $7.0 \times 10^{6}$ & 73 \\
\hline
\end{tabular}

and ratio $(73 \%)$ reach maximum when the height is within $5 \mathrm{~km}$ above MSL.

\section{Conclusions and Recommendations}

The 30 arc sec $(90 \mathrm{~m})$ high-resolution DEM data are used with a model for beam propagation estimated in a standard atmosphere to calculate beam occultation and the effective coverage maps of the Chinese national weather radar network. The main findings of this study are as follows:

(1) The coverage map at $1 \mathrm{~km}$ AGL shows extremely limited coverage especially in the mountainous west such as the Qinghai-Tibet Plateau and the YunnanGuizhou Plateau.

(2) At $2 \mathrm{~km} \mathrm{AGL}$, the coverage extent improves for radars deployed in eastern and central China, covering most of those areas. In particular, the Yangtze River Delta and the Pearl River Delta are generally sampled by more than 3 radars. However, the radars are still insufficient to estimate precipitation that occurs on the Qinghai-Tibet Plateau.

(3) At a height of $3 \mathrm{~km}$ AGL, CINRAD network provides good coverage east of $105^{\circ} \mathrm{E}$ although there is no radar coverage in many regions of the Inner Mongolia Autonomous Region. There are still large parts in western China with no radar coverage, which poses challenges in estimating precipitation.

(4) At $3 \mathrm{~km}$ above MSL, the radar coverage map (Figure 7(a)) is significantly different from the one at
$3 \mathrm{~km}$ AGL (Figure 6(c)) over the mountainous west due to radar sittings at high altitudes, while the coverage remains good in eastern and central China.

(5) At $5 \mathrm{~km}$ above MSL, the CINRAD network shows much better coverage than at $3 \mathrm{~km}$ above MSL and thus can monitor most areas in China except the Qinghai-Tibet Plateau, the Inner Mongolia province, and the southeast of Xinjiang province. There are more than 4 radars overlapping in the North China Plain, southern China, eastern Sichuan province, and the Yangtze River Delta.

With the rapid economic development of China in recent years, many high buildings have been constructed throughout the country, which can cause additional blockages to the radar beams. These anthropogenic changes are not represented in the DEM used in this study and thus not represented in the coverage maps presented herein. Although there are some limitations, this study can provide a reference for the future construction of the CINRAD network in China (e.g., identifying areas where radar coverage is insufficient to add a new radar or using our model to select candidate sites for radar construction) and radar coverage maps could be used to guide radar data mosaicking schemes in the future. If we can attain the latest DEM data with higher accuracy (e.g., $10 \mathrm{~m}$ or higher resolution DEM data) or add the heights of newly built high buildings into the DEM, the beam propagation simulations will be improved. It is recommended that users identify and document additional blockages by examining long-term precipitation accumulations or reflectivity frequency maps. However, these radar datasets are not presently available.

\section{Data Availability}

The 30 arc sec $(90 \mathrm{~m})$ Shuttle Radar Topography Mission (SRTM) high-resolution digital elevation model (DEM) data used to depict the terrain over China are available at http:// srtm.csi.cgiar.org/SELECTION/inputCoord.asp. The latitude, longitude, and elevation information of radar stations as well as radar reflectivity data is confidential. 


\section{Conflicts of Interest}

The authors declare that there are no conflicts of interest regarding the publication of this paper.

\section{Acknowledgments}

This research was partially sponsored by the " 100 Top Talents Program" (74110-52601108) at Sun Yat-Sen University, Guangzhou, Guangdong, China; "100 Top Talents Program" of Guangxi Zhuang Autonomous Region, Guangxi Scientific Technology Development Program (2014DD29090); HighLevel Talents Training and Teacher Qualities and Skills Promotion Plan for Guangxi Colleges and Universities (8844); the National Natural Science Foundation of China (41875182, 51579162, 41661021, and 41866001); and Guangxi Natural Fund of Innovative Team Project (2016JJF15001). Thanks are given to assistant engineer Mingfeng Li at Ruili Meteorological Bureau and Dr. Zhiheng Liao at School of Atmospheric Sciences, Sun Yat-Sen University, for their help in processing partial codes and valuable advice.

\section{References}

[1] V. V. Kharin, F. W. Zwiers, X. Zhang, and G. C. Hegerl, "Changes in temperature and precipitation extremes in the IPCC ensemble of global coupled model simulations," Journal of Climate, vol. 20, no. 8, pp. 1419-1444, 2007.

[2] P. A. O'Gorman and T. Schneider, "The physical basis for increases in precipitation extremes in simulations of 21stcentury climate change," Proceedings of the National Academy of Sciences, vol. 106, no. 35, pp. 14773-14777, 2009.

[3] Y. Sun, S. Solomon, A. Dai, and R. W. Portmann, "How often will it rain?," Journal of Climate, vol. 20, no. 19, pp. 4801-4818, 2007.

[4] B. Geng and M. Katsumata, "Beam blockage identification for weather radars on board the R/V Mirai using archived data," JAMSTEC Report of Research and Development, vol. 22, pp. 1-12, 2016.

[5] T. Pellarin, G. Delrieu, G.-M. Saulnier, H. Andrieu, B. Vignal, and J.-D. Creutin, "Hydrologic visibility of weather radar systems operating in mountainous regions: case study for the ardèche catchment (France)," Journal of Hydrometeorology, vol. 3, no. 5, pp. 539-555, 2002.

[6] G. E. Klazura and D. A. Imy, "A description of the initial set of analysis products available from the NEXRAD WSR-88d system," Bulletin of the American Meteorological Society, vol. 74, no. 7, pp. 1293-1311, 1993.

[7] R. T. Bruintjes, T. L. Clark, and W. D. Hall, "Interactions between topographic airflow and cloud/precipitation development during the passage of a winter storm in Arizona," Journal of the Atmospheric Sciences, vol. 51, no. 1, pp. 48-67, 1994.

[8] J. D. Marwitz, "The kinematics of orographic airflow during sierra storms," Journal of the Atmospheric Sciences, vol. 40, no. 5, pp. 1218-1227, 1983.

[9] R. M. Rauber, "Microphysical structure and evolution of a central sierra Nevada orographic cloud system," Journal of Applied Meteorology, vol. 31, no. 1, pp. 3-24, 1992.

[10] R. A. Maddox, J. Zhang, J. J. Gourley, and K. W. Howard, "Weather radar coverage over the contiguous United States," Weather and Forecasting, vol. 17, no. 4, pp. 927-934, 2002.
[11] K. J. Westrick, C. F. Mass, and B. A. Colle, "The limitations of the WSR-88D radar network for quantitative precipitation measurement over the coastal western United States," Bulletin of the American Meteorological Society, vol. 80, no. 11, pp. 2289-2298, 1999.

[12] W. F. Krajewski, A. A. Ntelekos, and R. Goska, "A GIS-based methodology for the assessment of weather radar beam blockage in mountainous regions: two examples from the US NEXRAD network," Computers \& Geosciences, vol. 32, no. 3, pp. 283-302, 2006.

[13] P. A. Kucera, W. F. Krajewski, and C. B. Young, "Radar beam occultation studies using GIS and DEM technology: an example study of Guam," Journal of Atmospheric and Oceanic Technology, vol. 21, no. 7, pp. 995-1006, 2004.

[14] R. Minciardi, R. Sacile, and F. Siccardi, "Optimal planning of a weather radar network," Journal of Atmospheric and Oceanic Technology, vol. 20, no. 9, pp. 1251-1263, 2003.

[15] M. Inggs, G. Lange, and Y. Paichard, "A quantitative method for mono- and multi-static radar coverage area prediction," in Proceedings of the IEEE National Radar Conference, pp. 707-711, Washington, DC, USA, May 2010.

[16] J. Bech, B. Codina, J. Lorente, and D. Bebbington, "The sensitivity of single polarization weather radar beam blockage correction to variability in the vertical refractivity gradient," Journal of Atmospheric and Oceanic Technology, vol. 20, no. 6, pp. 845-855, 2003.

[17] J. Bech, U. Gjertsen, and G. Haase, "Modelling weather radar beam propagation and topographical blockage at northern high latitudes," Quarterly Journal of the Royal Meteorological Society, vol. 133, no. 626, pp. 1191-1204, 2007.

[18] A. Fornasiero, J. Bech, and P. P. Alberoni, "Enhanced radar precipitation estimates using a combined clutter and beam blockage correction technique," Natural Hazards and Earth System Sciences, vol. 6, no. 5, pp. 697-710, 2006.

[19] P. C. Shakti, M. Maki, S. Shimizu et al., "Correction of reflectivity in the presence of partial beam blockage over a mountainous region using X-band dual polarization radar," Journal of Hydrometeorology, vol. 14, no. 3, pp. 744-764, 2013.

[20] C. B. Young, B. R. Nelson, A. A. Bradley et al., "An evaluation of NEXRAD precipitation estimates in complex terrain," Journal of Geophysical Research: Atmospheres, vol. 104, no. D16, pp. 19691-19703, 1999.

[21] H. Yang, P. Zhang, M. Cheng et al., "The valid mosaic data region of the CINRAD network," Journal of Applied Meteorological Science, vol. 20, no. 1, pp. 47-55, 2009, in Chinese.

[22] S. Wang, C. Pei, Z. Guo, and N. Shao, "Evaluations on Chinese next generation radar coverage and terrain blockage based on STRM data," Climatic and Environment Research, vol. 16, no. 4, pp. 459-468, 2011, in Chinese.

[23] S. Chen, Y. Tian, A. Behrangi et al., "Precipitation spectra analysis over China with high-resolution measurements from optimally merged satellite/gauge observations-part I: spatial and seasonal analysis," IEEE Journal of Selected Topics in Applied Earth Observations and Remote Sensing, vol. 9, no. 7, pp. 2966-2978, 2016.

[24] S. Chen, A. Behrangi, Y. Tian et al., "Precipitation spectra analysis over China with high-resolution measurements from optimally-merged satellite/gauge observations-Part II: diurnal variability analysis," IEEE Journal of Selected Topics in Applied Earth Observations and Remote Sensing, vol. 9, no. 7, pp. 2979-2988, 2016.

[25] J. Zhang, Y. Qi, D. Kingsmill, and K. Howard, "Radar-based quantitative precipitation estimation for the cool season in complex terrain: case studies from the NOAA 
hydrometeorology testbed," Journal of Hydrometeorology, vol. 13, no. 6, pp. 1836-1854, 2012.

[26] J. Zhang and Y. Qi, "A real-time algorithm for the correction of brightband effects in radar-derived QPE," Journal of Hydrometeorology, vol. 11, no. 5, pp. 1157-1171, 2010.

[27] R. E. Rinehart, Radar for Meteorologists, University of North Dakota, Grand Forks, North Dakota, USA, 2rd edition, 1991.

[28] V. Chandrasekar, Y. Wang, and H. Chen, "The CASA quantitative precipitation estimation system: a five year validation study," Natural Hazards and Earth System Sciences, vol. 12, no. 9, pp. 2811-2820, 2012.

[29] Y. Gou, Y. Ma, H. Chen, and Y. Wen, "Radar-derived quantitative precipitation estimation in complex terrain over the eastern Tibetan Plateau," Atmospheric Research, vol. 203, pp. 286-297, 2018. 

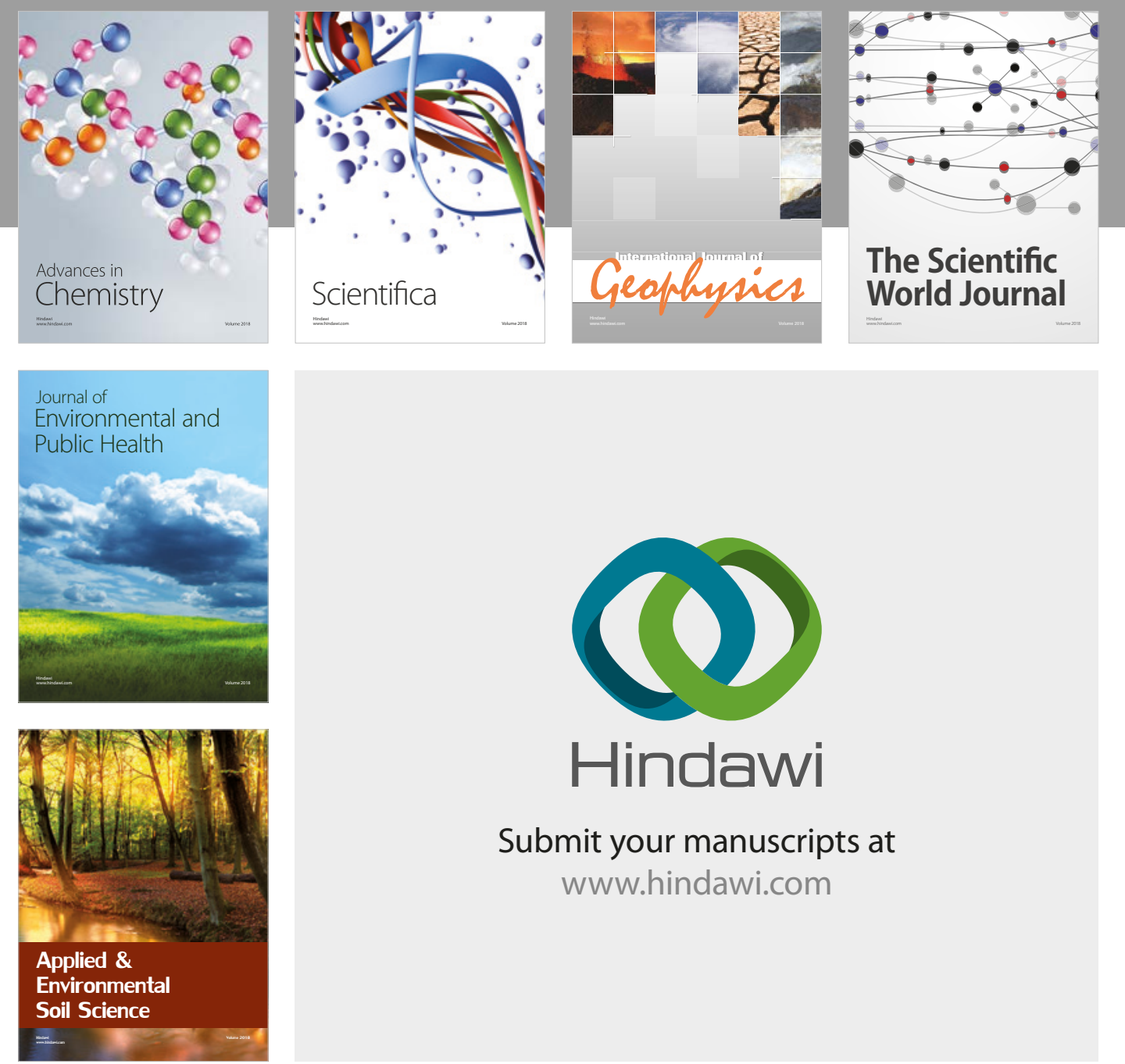

The Scientific

\section{World Journal}
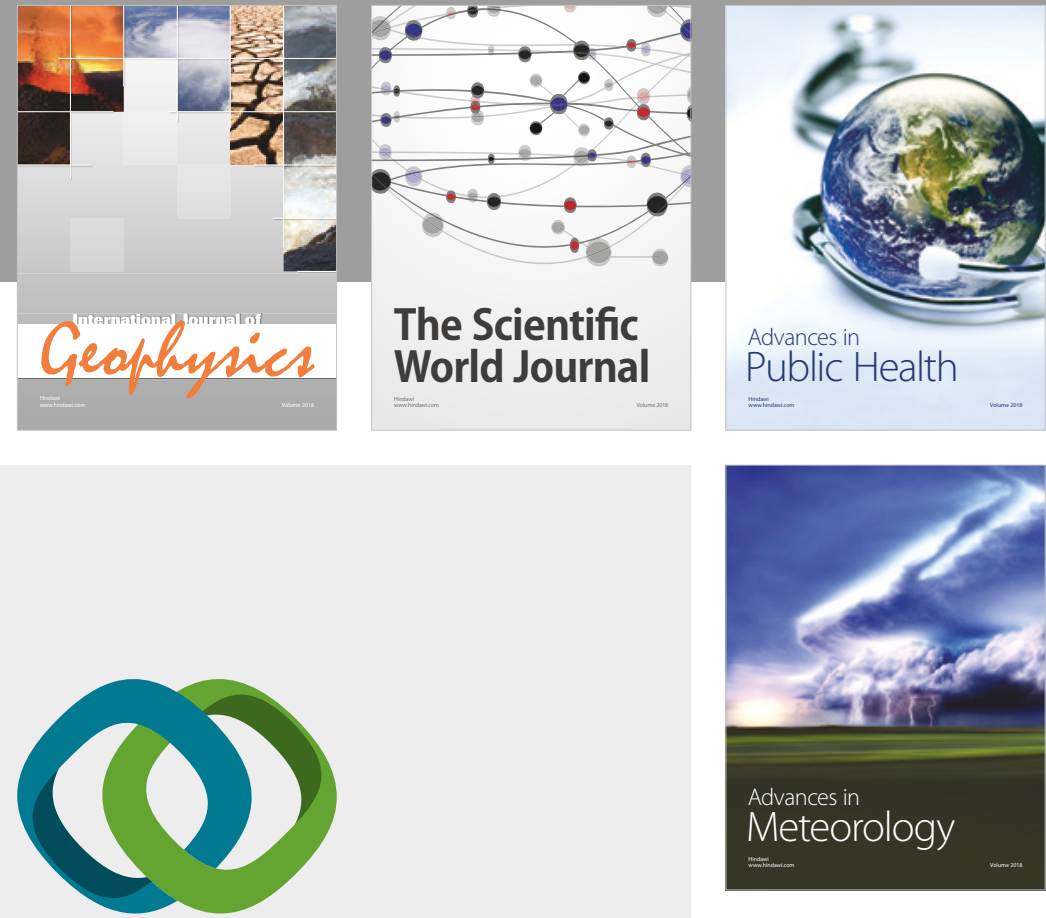

Advan

Public Health

\section{Hindawi}

Submit your manuscripts at

www.hindawi.com
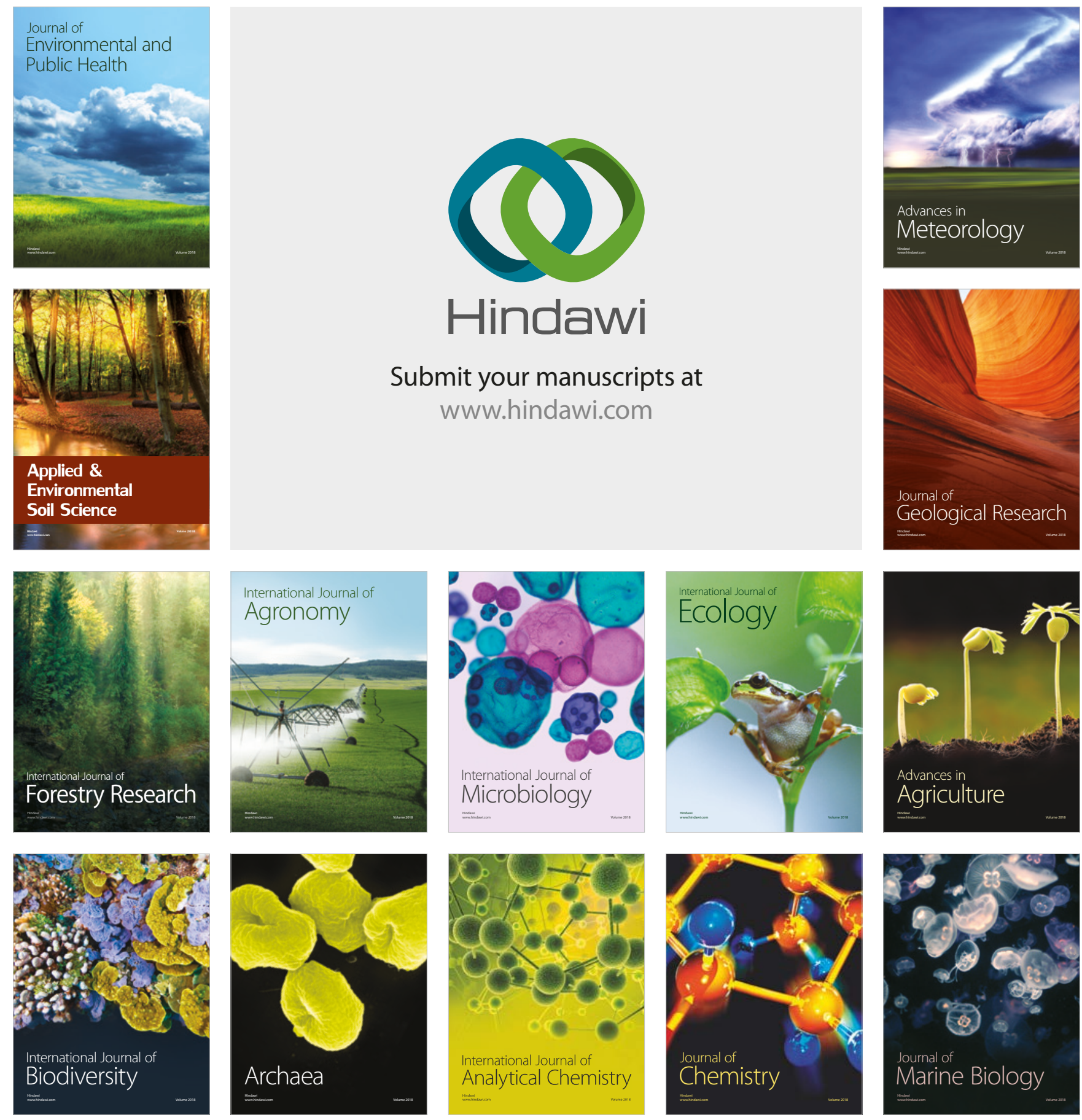